\title{
LOCATIONAL MARGINAL PRICING FRAMEWORK IN SECURED DISPATCH SCHEDULING UNDER CONTINGENCY CONDITION
}

\author{
R.Manikamdan ${ }^{1}$, M.Bhoopathi ${ }^{2}$, R.Saravanakumar ${ }^{3}$ \\ ${ }^{I} P G$ Student, Department of EEE, Jayaram College of Engineering and Technology, TamilNadu, India \\ ${ }^{2}$ Assistant Professor, Department of EEE, Jayaram College of Engineering and Technology, TamilNadu, India \\ ${ }^{3}$ Assistant Professor, Department of EEE, Sudharsan Engineering college, TamilNadu, India
}

\begin{abstract}
This paper is to design the locational marginal pricing [LMP] under security constrained condition. The pricing framework of the regulated power market has same for normal and the contingency condition. So whenever the maximum power used from the customer, the massive blackouts occurs in the power system network due to exceeds the transmission limits. In deregulated power market having the LMP pricing method. The LMP is mainly used for contingency condition pricing of load at each location in secured manner. And also reduce the cost of the minimum load usage customer. Line outage and generation outage is consider in contingency analysis in security constrained optimal power flow and to calculate LMP in each location (bus) in IEEE-14 bus system by using power world simulator.
\end{abstract}

Keywords: Blackouts, Contingency, Line Outage, Generation Outage, Locational Marginal Pricing.

\section{INTRODUCTION}

The recent vertically integrated power market consists of bundled generation, transmission, distribution [1]. And only one seller and many buyers in the regulated power system. The pricing of power transmission is constant at all conditions and there is no incentive for minimum load user of each location. So we introduce the deregulation of power system network to lowering the utility rates, customer specific services, and encourage the renewable sources. In deregulated power market is mainly for reduction of cost and to design the pricing rates of all the load entities and give some incentives to the minimum load usage customer for demand response improvement [2]. Due to open access and lower cost transmission in deregulation, the competition is occurring in the transmission network. So the transmission of power exceeds the transfer limits, that time contingency create in the power system network $[1,2]$.

The contingency can be classified as line outage, generator outage, transformer outage etc. under contingency condition the security of the power system is collapsed, that time massive blackouts is occurred. So security analysis of power system network is important task in deregulation [3]. Before security -constrained optimal power flow we have to find the contingency analysis form to predict the outages in power system. And to include the contingency analysis form in the security-constrained optimal power flow solution [2]

The power system is highly non-linear system which operates in a constantly changing environment such as load, generator output, topology and key operating parameters which changes continuously. Due to secured limits of the power system network, the cost will be varied by adding the congestion cost in contingency condition [4]. So the LMP pricing framework is important in both normal and contingency condition. Most of the security analysis is based on state estimation of power system, but we introduce the new approach for security analysis and LMP pricing calculation [5].

In this paper proposed to new method solution of marginal cost of the each location (bus) in both normal and contingency condition and we have to calculate the congestion cost in contingency condition of each location(bus) is calculated through security constrained optimal power floe using power world simulator. The power world simulator is highly essential tool for marginal cost evaluation in the easy manner. There is no complicate equation design and coding. The output response time is maximum than compared with others. Full Newton's method is used for the power flow solution and binding the constraints also included. The mathematical Problem formulation is in section II. The locational marginal pricing framework algorithm in power world simulator is in section III. The description of test system in section IV In section V includes simulation results and description. Conclusion from the results in section VI

\section{PROBLEM FORMULATION}

\subsection{Power Flow Equation (N-R Method)}

The power world simulator can be set to use a full Newton solution or use a DC load flow method to analyze each 
contingency. The full Newton approach is not as fast as a DC load flow, but the results tend to be significantly more accurate and allow for gauging voltage/VAR effects. The Newton solution method (also called Newton-Rapson method) is more efficient for large power systems. The number of iteration required to obtain a solution is independent of a system size but more functional evaluation are required at each iteration

Equation for bus Admittance matrix

$$
\mathrm{I}_{\mathrm{i}}=\sum_{j=1}^{n} Y_{\mathrm{ij}} \mathrm{V}_{\mathrm{j}}
$$

In above equation $\mathrm{j}$ includes bus $\mathrm{i}$ expressing this equation in polar form, we have

$$
\mathrm{I}_{\mathrm{i}}=\sum_{j=1}^{n}\left|Y_{\mathrm{ij}}\right|\left|\mathrm{V}_{\mathrm{j}}\right| \angle \theta_{\mathrm{ij}}+\delta_{\mathrm{j}}
$$

The complex power at bus

$$
\mathrm{P}_{\mathrm{i}}-\mathrm{Q}_{\mathrm{i}}=\mathrm{V}_{\mathrm{i}}^{*} \mathrm{I}_{\mathrm{i}}
$$

Substituting from (2) for $\mathrm{I}_{\mathrm{i}}$ in (3)

$$
\mathrm{P}_{\mathrm{i}}-\mathrm{Q}_{\mathrm{i}}=\left|\mathrm{V}_{\mathrm{i}}\right| \angle-\delta_{\mathrm{i}} \sum_{j=1}^{n}\left|Y_{\mathrm{ij}}\right|\left|\mathrm{V}_{\mathrm{j}}\right| \angle \theta_{\mathrm{ij}}+\delta_{\mathrm{j}}
$$

Separating the real and imaginary parats

$$
\begin{aligned}
& P_{\mathrm{i}}=\sum_{j=1}^{n}\left|V_{i}\right|\left|V_{j}\right|\left|Y_{i j}\right| \cos \left(\theta_{i j}-\delta_{i+} \delta_{j}\right) \\
& Q_{i}=-\sum_{j=1}^{n}\left|V_{i}\right|\left|V_{j}\right|\left|Y_{i j}\right| \sin \left(\theta_{i j}-\delta_{i+} \delta_{j}\right)
\end{aligned}
$$

Equation (5) and (6) constitute of nonlinear algebraic equation in terms of the independent variables, voltage magnitude in per unit and phase angle in radians.

$$
\begin{aligned}
& {\left[\begin{array}{c}
\Delta P_{2}{ }^{(k)} \\
\vdots \\
\Delta P_{n}{ }^{(k)} \\
\Delta Q_{2}{ }^{(k)} \\
\vdots \\
\Delta Q_{n}{ }^{(k)}
\end{array}\right]=}
\end{aligned}
$$

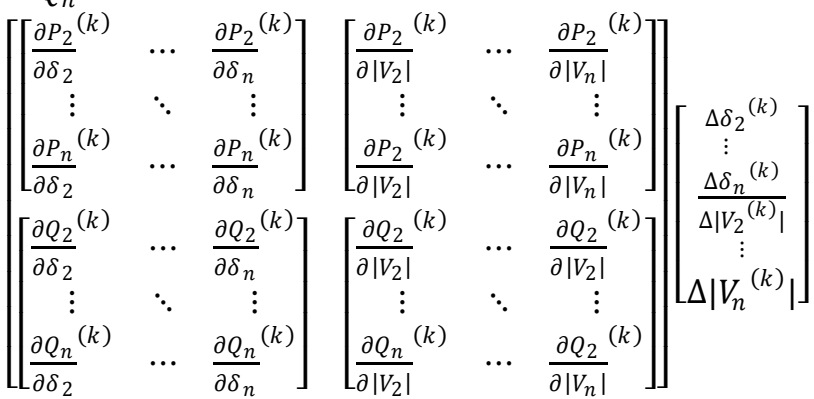

In above equation, bus 1 is assumed to be slack bus. The jacobian matrix gives the linearized relationship between small changes in voltage angle $\Delta \delta_{i}{ }^{(k)}$ and voltage magnitude $\Delta\left|V_{i}{ }^{(k)}\right|$ with small changes in real and reactive power $\Delta P_{i}{ }^{(k)}$ and $\Delta Q_{i}{ }_{i}^{(k)}$ elements of jacobian matrix are the partial derivatives of (5) and (6) evaluated at $\Delta \delta_{i}{ }^{(k)}$ and $\Delta\left|V_{i}{ }^{(k)}\right|$.

$$
\left[\begin{array}{l}
\Delta P \\
\Delta Q
\end{array}\right]=\left[\begin{array}{ll}
J_{1} & J_{2} \\
J_{3} & J_{4}
\end{array}\right]\left[\begin{array}{c}
\Delta \delta \\
\Delta|V|
\end{array}\right]
$$

Accordingly there are (n-1) real power constraints and (n-1-m) reactive power constraints and the jacobian matrix is the order of $(2 n-2-m)(2 n-2-m)$.

$J_{1}$ is the order of $(n-1) \times(n-1)$

$$
\begin{aligned}
& \frac{\partial P_{i}}{\partial \delta_{i}}=\sum_{j \neq 1}^{n}\left|V_{i}\right|\left|V_{j}\right|\left|Y_{i j}\right| \sin \left(\theta_{i j}-\delta_{i+} \delta_{j}\right) \\
& \frac{\partial P_{i}}{\partial \delta_{j}}=-\left|V_{i}\right|\left|\mathrm{V}_{\mathrm{j}}\right|\left|\mathrm{Y}_{\mathrm{ij}}\right| \sin \left(\theta_{i j}-\delta_{i+} \delta_{j}\right) \mathrm{j} \neq 1
\end{aligned}
$$

$J_{2}$ is the order of $(n-1) \times(n-1-m)$

$$
\begin{gathered}
\frac{\partial P_{i}}{\partial\left|V_{i}\right|}=2\left|V_{i}\right|\left|Y_{i i}\right| \cos \theta_{i i}+\underset{j \neq 1}{\sum_{j}^{n}\left|V_{i}\right|\left|V_{j}\right|\left|Y_{i j}\right| \cos \mid\left(\theta_{i j}-\delta_{i+} \delta_{j}\right)} \\
\frac{\partial P_{i}}{\partial\left|V_{j}\right|}=\left|V_{i}\right|\left|Y_{i j}\right| \cos \left(\theta_{i j}-\delta_{i+} \delta_{j}\right) \quad \mathrm{j} \neq i
\end{gathered}
$$

$J_{3}$ is the order of $(n-1-m) x(n-1)$

$$
\frac{\partial Q_{i}}{\partial \delta_{i}}=\sum_{j \neq 1}^{n}\left|V_{i}\right|\left|V_{j}\right|\left|Y_{i j}\right| \cos \left(\theta_{i j}-\delta_{i+} \delta_{j}\right)
$$

$J_{4}$ is the order of $(n-1-m) \times(n-1-m)$

$$
\begin{gathered}
\frac{\partial Q_{i}}{\partial \delta_{j}}=-\left|V_{i}\right|\left|V_{\mathrm{j}}\right|\left|\mathrm{Y}_{\mathrm{ij}}\right| \cos I\left(\theta_{i j}-\delta_{i+} \delta_{j}\right) \mathrm{j} \neq i \\
\frac{\partial Q_{i}}{\partial\left|V_{i}\right|}=\left|V_{i}\right|\left|Y_{i i}\right| \sin \theta_{i i}-\sum_{j \neq 1}^{n}\left|V_{j}\right|\left|Y_{i j}\right| \sin \left(\theta_{i j}-\delta_{i+} \delta_{j}\right) \\
\frac{\partial Q_{i}}{\partial\left|V_{j}\right|}=-\left|V_{i}\right|\left|Y_{i j}\right| \sin \left(\theta_{i j}-\delta_{i+} \delta_{j}\right) \mathrm{j} \neq i
\end{gathered}
$$

The terms $\Delta P_{i}{ }^{(k)}$ and $\Delta \mathrm{Q}_{\mathrm{i}}{ }^{(\mathrm{k})}$ are difference between the schedule and calculated values, known as the power residuals, given by

$$
\begin{gathered}
\Delta P_{i}{ }^{(k)}=\mathrm{P}_{\mathrm{i}}^{\text {sch }}-\mathrm{P}_{\mathrm{i}}{ }^{(\mathrm{k})} \\
\Delta Q_{i}{ }^{(k)}=\mathrm{Q}_{\mathrm{i}}{ }^{\mathrm{sch}}-\mathrm{Q}_{\mathrm{i}}{ }^{(\mathrm{k})}
\end{gathered}
$$

The new estimated for bus voltage $\mathrm{i}$

$$
\delta_{i}^{(k+1)}=\delta_{i}^{(k)}+\Delta \delta_{i}^{(k)}
$$




$$
\left|V_{i}^{(k+1)}\right|=\left|V_{i}^{(k)}\right|+\Delta\left|V_{i}^{(k)}\right|
$$

\subsection{Security Constrained Optimal Power Flow}

Objective function

$\operatorname{Min} f(p)$

Subject to $g(p)=\underline{0}$

$\mathrm{h}_{\min } \leq \mathrm{h}(\mathrm{p}) \leq \mathrm{h}_{\max }$ in normal condition constraints

$\mathrm{h}^{\prime}{ }_{\min } \leq \mathrm{h}^{\prime}(\mathrm{p}) \leq \mathrm{h}_{\max }{ }_{\operatorname{man}}$ in contingency condition constraints.

Security constrained optimal power flow solution (SCOPF) will always a cost $\geq$ optimal power flow cost. If we ignore losses, then we can say that an OPF solution differs from an EDC solution only when a normal transmission constraint. When normal flow moves from just $<100 \%$ to $\geq 100 \%$ of continuous rating

SCOPF differs from an OPF solution only when contingency constraint becomes binding occurs when post- contingency flow moves from just $<100 \%$ to $\geq 100 \%$ of emergency rating.

Now let's consider the SCOPF. Its problem statement is given as problem $\mathrm{P}_{\mathrm{p}}$ :

$$
\begin{gathered}
\operatorname{Min} \mathrm{f}\left(\mathrm{x}_{0}, \mathrm{u}_{0}\right) \\
\mathrm{g}_{\mathrm{k}}\left(\mathrm{x}_{\mathrm{k}}, \mathrm{u}_{\mathrm{k}}\right)=0 \\
\mathrm{~h}_{\mathrm{k}}\left(\mathrm{x}_{\mathrm{k}}, \mathrm{u}_{\mathrm{k}}\right)=\mathrm{h}_{\mathrm{k}}^{\max } \quad \mathrm{k}=0,1,2, \ldots \mathrm{c}
\end{gathered}
$$

Notice that there are $\mathrm{C}$ contingencies to be addressed in the SCOPF and that there are a complete new set of constraints for each of these $\mathrm{C}$ contingencies observe. Each of contingency related equality constraints is exactly like the original set of equality constraints except if corresponds the system with an element removed.

Each set of contingency related inequality-constraints is exactly like the original set of inequality constraints except its corresponds to the system with an element removed and branch flow constraints and for voltage magnitudes, the limits will be different.

Also notice that the constraints are a function of $x_{k}$, the voltage magnitudes and angles under the pre-contingency $(\mathrm{k}=0)$ and contingency condition $(\mathrm{k}>1,2, \ldots . \mathrm{c})$ and $\mathrm{u}_{0}$.

\subsection{Locational Marginal Pricing Calculation}

Locational marginal pricing $\left(\mathrm{LMP}_{\mathrm{s}}\right)$ are determined from the result of a security-constrained least-cost dispatch. It is a taxi ride for MW. It may differs in the various location(bus). We need two factors to deside the locational marginal pricing.

(i)Transmission congestion

(ii)Losses
The Locational Marginal Pricing (nodel price) at bus i can be calculated using the following equation

$$
\begin{gathered}
\underset{\mathrm{LMP}}{\mathrm{LMarginal}} \mathrm{l}_{\text {cost }}+\text { congestion }_{\text {cost }}+\text { losses }_{\text {cost }} \\
\begin{array}{c}
\lambda_{\mathrm{i}} \\
=
\end{array} \\
\lambda_{\text {Ref }}+\lambda_{\text {Congest }}+\lambda_{\text {Lossi }} \\
\lambda_{\mathrm{i}}=\lambda_{\text {Ref }}-\mathrm{L}_{\mathrm{i}} \times \lambda_{\text {Ref }}-\sum_{j}(\mu j X S F j i)
\end{gathered}
$$

$\lambda_{\text {Lossi }}=\left(-\mathrm{L}_{\mathrm{i}} \times \lambda_{\text {Ref }}\right)-$ losses from the reference bus to bus $\mathrm{i}$ $=\left(+\mathrm{L}_{\mathrm{i}} \times \lambda_{\text {Ref }}\right)-$ losses from bus $\mathrm{i}$ to reference bus

$\lambda_{\text {Congest }}=\left(-\sum_{j}(\mu j X S F j i)-\right.$ congestion from reference bus to bus i

reference bus.

$$
=\left(+\sum_{j}(\mu j X S F j i)-\text { congestion from bus } \mathrm{I}\right. \text { to }
$$

\section{LMP ALGORITHM IN POWER WORLD SIMULATOR}

\subsection{Locational Marginal Pricing Algorithm}

Step 1: Draw the simulink one line diagram in new case window of power world simulator for the given power system in edit mode.

Step 2: Set the cubic cost of each generation and to convert piece wise linear cost.

Step 3: Save the case with apt name.

Step 4: Select tools in run mode and to solve the power flow by using full N-R method.

Step 5: Open Add-ons Ribbon Tab

Step 6: To select the OPF case information of the

Dialog box and to select the all OPF area records.

a.) If OPF records "YES" that record is included in the marginal cost calculation.

b.) If OPF records "NO" that records is not include in the marginal cost calculation.

Step 7: To set all the OPF constraints and also include common constraints.

Step 8: Open the SCOPF dialog box in the add-ons ribbon tab.

Step 9: Run Full security constrained OPF under normal condition (zero contingency in contingency analysis form)

Step10: To calculate marginal cost of each bus (location) before contingency.

Step11: To view contingency analysis form in the SCOPF dialog box.

Step12: Right click on label and select auto insert contingencies through insert special option.

Step 13: Verify that single transmission line or transformer is selected.

Step 14: If can limit the contingencies inserted to only those meeting define filter.

Step 15: we want to insert contingencies for all branches and generators so no filtering is desired.

Step 16: To check the following conditions

a.) Remove the checkmarks in use area/zone filters. 
b.) Verify no other options are selected.

Step 17: Click Do insert contingencies button to accept the all contingencies.

Step 18: Click "YES" to get the contingencies.

Step 19: Now the contingency analysis dialog shows contingencies

a.) Right click on the list display on the contingency tap and select insert special and click auto insert to the local menu.

b.) Select single generating unit then click the do insert contingency button. Click "YES" to complete.

Step 20: Click "Start Run" on the contingency tab and close the tab.

Step 21: The contingency elements are include in the SCOPF dialog box.

Step 21: To Run the Full Security Constrained optimal power Flow.

Step 22: We get the marginal cost under contingency condition. In addition congestion, transmission loss cost in each location (bus)

\section{TEST SYSTEM}

The Locational marginal pricing of 14-bus test system is shown below when the power flow is running on the power world simulator. The percentage of power flow is mentioned in power flow diagram. It consists of five generators for dispatch of power.

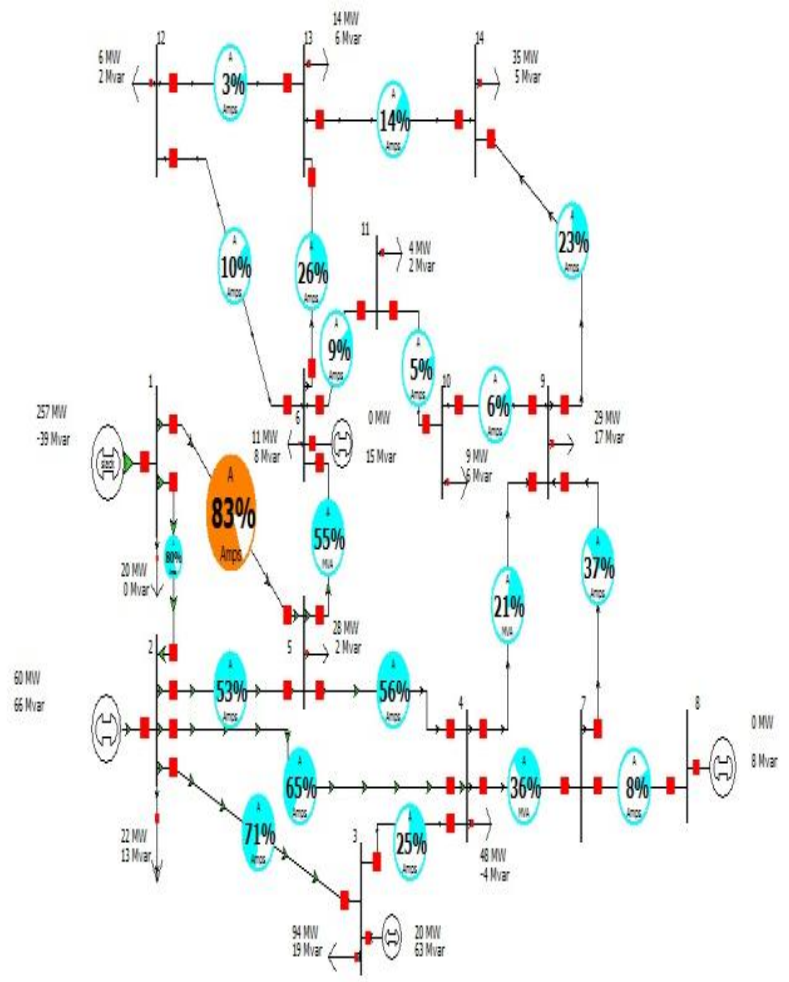

Fig. 1 IEEE-14 bus system

\section{SIMULATION RESULTS}

Locational marginal pricing (LMP) is important in deregulated power market under normal and contingency condition. So we calculate the LMP by considering without contingency, line outage, generation outage and also include all contingency. First we find the contingency elements in IEEE-14 bus system.

Table.1 Single contingency of line \& generator

\begin{tabular}{|c|c|c|c|}
\hline Label & Violations & $\begin{array}{c}\text { Max } \\
\text { Branch \% }\end{array}$ & Min Voltage \\
\hline $\begin{array}{c}\text { L_0000011- } \\
\text { 0000022C1 }\end{array}$ & 2 & 276.5 & - \\
\hline $\begin{array}{c}\text { L_0000011- } \\
\text { 0000055C1 }\end{array}$ & 1 & 127.5 & - \\
\hline $\begin{array}{c}\text { L_0000022- } \\
\text { 0000033C1 }\end{array}$ & 2 & 102.0 & - \\
\hline $\begin{array}{c}\text { L_00000022- } \\
\text { 0000044C1 }\end{array}$ & 1 & 102.0 & - \\
\hline $\begin{array}{c}\text { L_0000022- } \\
\text { 0000055C1 }\end{array}$ & 1 & 103.0 & - \\
\hline $\begin{array}{c}\text { L_0000066- } \\
\text { 00001313C1 }\end{array}$ & 2 & - & 0.898 \\
\hline $\begin{array}{c}\text { L_0000099- } \\
\text { 00001414C1 }\end{array}$ & 1 & - & 0.848 \\
\hline $\begin{array}{c}\text { G_0000022U } \\
1\end{array}$ & 1 & 103.6 & - \\
\hline
\end{tabular}

Table.2 Multiple contingency of both line and Generator

\begin{tabular}{|c|c|c|c|}
\hline Label & Violations & $\begin{array}{c}\text { Max } \\
\text { Branch } \\
\%\end{array}$ & Min Voltage \\
\hline $\begin{array}{c}\text { G_0000022u1\& } \\
\text { L_0000022- } \\
\text { 0000033c1 }\end{array}$ & 3 & 115.7 & - \\
\hline $\begin{array}{c}\text { G_0000022u1\& } \\
\text { L_0000066- } \\
\text { 00001313c1 }\end{array}$ & 3 & 104.6 & 0.894 \\
\hline $\begin{array}{c}\text { G_0000033u1\& } \\
\text { L_0000011- } \\
\text { 0000022c1 }\end{array}$ & 4 & 325.3 & 0.891 \\
\hline $\begin{array}{c}\text { G_0000033u1\& } \\
\text { L_0000011- } \\
\text { 0000055c1 }\end{array}$ & 3 & 140.2 & - \\
\hline $\begin{array}{c}\text { G_0000033u1\& } \\
\text { L_0000022- } \\
\text { 0000033c1 }\end{array}$ & 6 & 118.0 & 0.739 \\
\hline $\begin{array}{c}\text { G_0000066u1\& } \\
\text { L_0000011- } \\
\text { 0000022c1 }\end{array}$ & 3 & 283.4 & 0.883 \\
\hline $\begin{array}{c}\text { G_0000066u1\& } \\
\text { L_0000077- }\end{array}$ & 5 & - & 0.842 \\
\hline
\end{tabular}




\begin{tabular}{|c|c|c|c|}
\hline $0000099 \mathrm{c} 1$ & & & \\
\hline G_0000066u1\& & & & \\
L_0000099- & 3 & - & 0.733 \\
$000001414 \mathrm{c} 1$ & & & \\
\hline
\end{tabular}

Table 3 LMP in Normal condition

\begin{tabular}{|l|l|l|l|l|l|}
\hline $\begin{array}{l}\text { Bus } \\
\text { No. }\end{array}$ & $\begin{array}{l}\text { Area } \\
\text { name }\end{array}$ & $\begin{array}{l}\text { Energy } \\
\text { cost } \\
(\$ / \mathrm{mwh})\end{array}$ & $\begin{array}{l}\text { Cong } \\
\text { cost } \\
(\$ / \mathrm{m} \\
\text { wh })\end{array}$ & $\begin{array}{c}\text { Loss } \\
\text { cost } \\
(\$ / \mathrm{mwh})\end{array}$ & $\begin{array}{c}\text { LMP } \\
(\$ / \mathrm{mwh})\end{array}$ \\
\hline 1 & Top & 11.28 & -0.00 & 0.00 & 11.28 \\
\hline 2 & Top & 11.28 & -0.00 & 0.72 & 12.00 \\
\hline 3 & Top & 11.28 & -0.00 & 1.72 & 12.99 \\
\hline 4 & Top & 11.28 & -0.00 & 1.60 & 12.87 \\
\hline 5 & Top & 11.28 & -0.00 & 1.39 & 12.66 \\
\hline 6 & Top & 11.28 & -0.00 & 1.39 & 12.67 \\
\hline 7 & Top & 11.28 & -0.00 & 1.63 & 12.90 \\
\hline 8 & Top & 11.28 & -0.00 & 1.63 & 12.90 \\
\hline 9 & Top & 11.28 & -0.00 & 1.64 & 12.92 \\
\hline 10 & Top & 11.28 & -0.00 & 1.68 & 12.96 \\
\hline 11 & Top & 11.28 & -0.00 & 1.59 & 12.86 \\
\hline 12 & Top & 11.28 & -0.00 & 1.67 & 12.94 \\
\hline 13 & Top & 11.28 & -0.00 & 1.84 & 13.11 \\
\hline 14 & Top & 11.28 & -0.00 & 2.51 & 13.79 \\
\hline
\end{tabular}

Locational marginal pricing of each bus system is in the above table. Ther is no congestion cost due to normal power flow condition.

Table 4 LMP in Contingency Condition (only includes single contingency).

\begin{tabular}{|l|l|l|l|l|l|}
\hline $\begin{array}{l}\text { Bus } \\
\text { No. }\end{array}$ & $\begin{array}{l}\text { Area } \\
\text { name }\end{array}$ & $\begin{array}{l}\text { Energy } \\
\text { cost } \\
(\$ / \mathrm{mwh})\end{array}$ & $\begin{array}{l}\text { Conge } \\
\text { cost } \\
(\$ / \mathrm{mw} \\
\mathrm{h})\end{array}$ & $\begin{array}{l}\text { Loss } \\
\text { cost } \\
(\$ / \mathrm{mwh} \\
)\end{array}$ & $\begin{array}{l}\text { LMP } \\
(\$ / \mathrm{mwh})\end{array}$ \\
\hline 1 & Top & 5.86 & 0.00 & 0.00 & 5.86 \\
\hline 2 & Top & 5.86 & 5.88 & 0.26 & 12.00 \\
\hline 3 & Top & 5.86 & 593.05 & 0.78 & 599.69 \\
\hline 4 & Top & 5.86 & 530.35 & 0.74 & 536.95 \\
\hline 5 & Top & 5.86 & 389.45 & 0.64 & 395.94 \\
\hline 6 & Top & 5.86 & 432.90 & 0.64 & 439.40 \\
\hline 7 & Top & 5.86 & 510.31 & 0.75 & 516.92 \\
\hline 8 & Top & 5.86 & 510.31 & 0.75 & 516.92 \\
\hline 9 & Top & 5.86 & 499.13 & 0.76 & 505.74 \\
\hline 10 & Top & 5.86 & 490.63 & 0.78 & 497.27 \\
\hline 11 & Top & 5.86 & 463.86 & 0.73 & 470.46 \\
\hline 12 & Top & 5.86 & 446.39 & 0.78 & 453.03 \\
\hline 13 & Top & 5.86 & 456.67 & 0.86 & 463.40 \\
\hline 14 & Top & 5.86 & 509.62 & 1.21 & 516.68 \\
\hline
\end{tabular}

The congestion cost is occurred in each bus due to single contingency of line outage and generation outage of each elements

Table 5 LMP price (includes all contingencies)

\begin{tabular}{|l|l|l|l|l|l|}
\hline $\begin{array}{l}\text { Bus } \\
\text { No. }\end{array}$ & $\begin{array}{l}\text { Area } \\
\text { name }\end{array}$ & $\begin{array}{l}\text { Energy } \\
\text { cost } \\
(\$ / \mathrm{mwh})\end{array}$ & $\begin{array}{l}\text { Conge } \\
\text { Cost } \\
(\$ / \mathrm{mwh})\end{array}$ & $\begin{array}{l}\text { Losses } \\
(\$ / \mathrm{mwh})\end{array}$ & $\begin{array}{c}\text { LMP } \\
(\$ / \mathrm{mwh})\end{array}$ \\
\hline 1 & Top & -1161.26 & 1167.12 & 0.00 & 5.86 \\
\hline 2 & Top & -1161.26 & 1223.32 & -50.06 & 12.00 \\
\hline 3 & Top & -1161.26 & 1610.35 & -152.80 & 296.29 \\
\hline 4 & Top & -1161.26 & 3318.47 & -144.14 & 2013.07 \\
\hline 5 & Top & -1161.26 & 1123.77 & -124.52 & -162.01 \\
\hline 6 & Top & -1161.26 & 14055.13 & -124.74 & $\begin{array}{l}12769.1 \\
3\end{array}$ \\
\hline 7 & Top & -1161.26 & 3572.12 & -146.98 & 2263.83 \\
\hline 8 & Top & -1161.26 & 3572.12 & -146.98 & 2263.88 \\
\hline 9 & Top & -1161.26 & 5166.58 & -148.48 & 3856.84 \\
\hline 10 & Top & -1161.26 & 13749.70 & -152.99 & $\begin{array}{l}12435.4 \\
5\end{array}$ \\
\hline 11 & Top & -1161.26 & 13944.48 & -143.86 & $\begin{array}{l}12639.3 \\
6\end{array}$ \\
\hline 12 & Top & -1161.26 & 14223.56 & -152.48 & $\begin{array}{l}12909.8 \\
2\end{array}$ \\
\hline 13 & Top & -1161.26 & 14038.94 & -169.60 & $\begin{array}{l}12708.0 \\
7\end{array}$ \\
\hline 14 & Top & -1161.26 & 12030.02 & -237.59 & 10631.1 \\
& & & & & 7 \\
\hline
\end{tabular}

In security constrained condition all single and multiple contingency elements are include in the power system. The LMP value is maximum due to congestion cost.

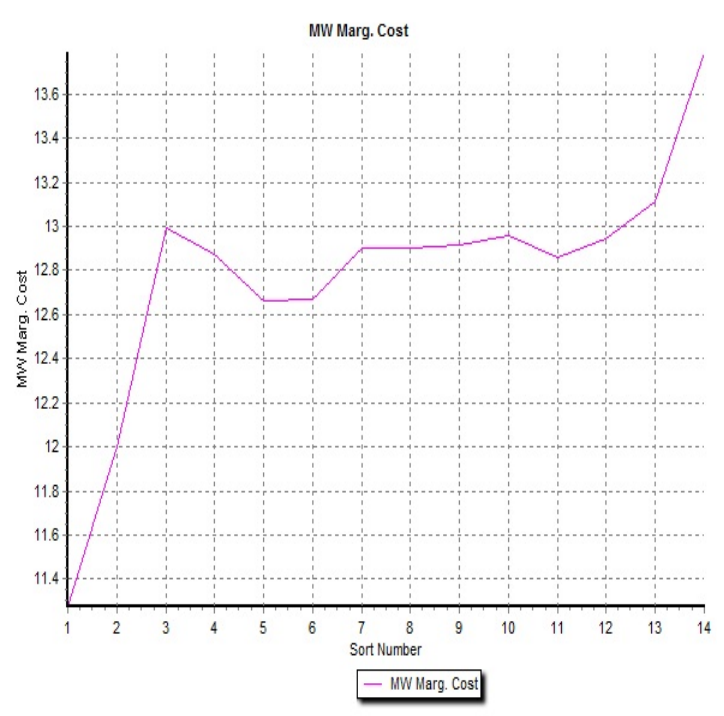

Fig. 2 LMP Cost Curve In Each Bus (before contingencies) 


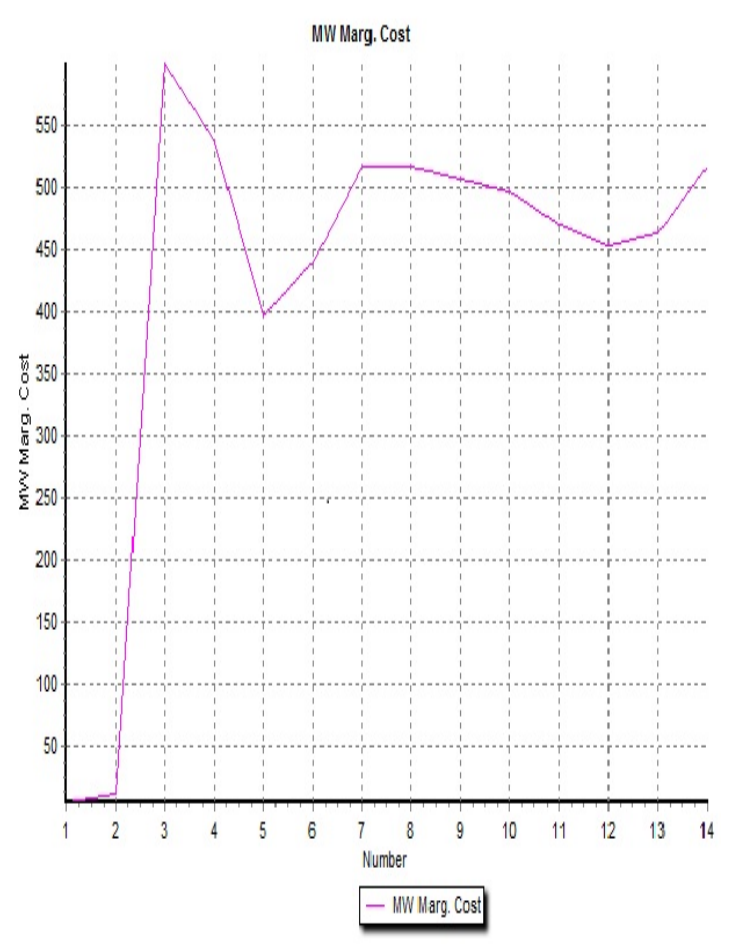

Fig.3 Lmp Cost Curve in Each Bus (only includes line outage and generator outage)

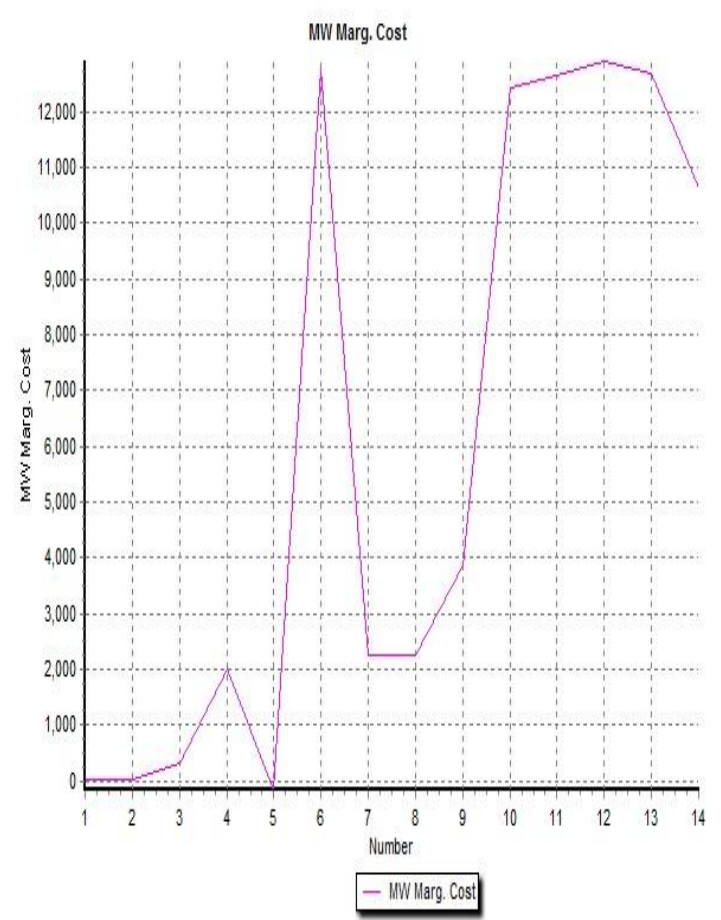

Fig .4 Lmp Cost Curve In Each Bus (includes all contingencies)

\section{CONCLUSIONS}

The state estimation based contingency analysis technique is more complex. But Newton's method based contingency analysis and security constrained optimal power flow in contingency condition is simple and more accuracy in power world simulator. The LMP calculation of test system is easy in power world simulation. In addition LMP is depends on congestion cost of each bus system. Whenever the contingency is occur in this system that time only congestion cost is added in LMP. Otherwise there is no congestion cost in the system. So the locational marginal pricing is reduced in the normal condition. The LMP calculation is helpful for demand response improvement under security condition in deregulated power market. In future we can easily reduce the cost of the power transmission and to improve the demand response in secured manner by using the reserve option and to connect from renewable generation to the transmission network. And we get minimum congestion cost in each location. So we can easily improve the demand response in the secured dispatch scheduling in both normal and the contingency condition in the power world simulator tool. It is user friendly software in the pricing calculation of deregulated power market in the power system network.

\section{REFERENCES}

[1]. Amit Kumar Roy "contingency analysis in power system" Thapur University Patiala.2009.

[2]. R.Manikandan, M.Bhoopathi " Contingency analysis in deregulated power market" Jayaram College of Engineering and Technology, Tamilnadu 2013.

[3]. Richard D.Christie, AnjanBose "load frequency control issues in power system operations after deregulation" University of Washington, 1995.

[4]. Saavedra, O.R., "Solving the security constrained optimal power flow problem in a distributed computing environment," Generation, transmission and distribution, IEEE proceedings, vol.143, No.6 pp 593-598, 1996.

[5]. Fangxing Li, Rui Bo, "Congestion and Price Prediction Under Load Variation,"IEEE Transaction on power system , Vol 24,No.2 May 2009.

\section{BIOGRAPHIES}

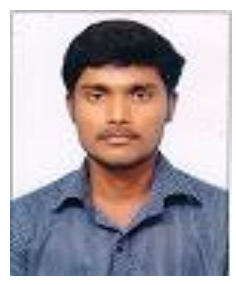

Manikandan $\mathbf{R}$ obtained his Bachelor degree in Electrical \& Electronics Engineering from P.R.Engineering College, Thanjavur in the year 2012 and Master degree in Power Systems Engineering doing from Jayaram College of Engineering and technology, Thuraiyur, India. His research area includes deregulation of power market and Smart grid technologies. 


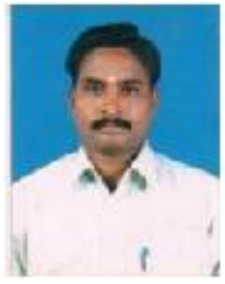

Bhoopathi $\mathbf{M}$ received his B.E. degree in Electrical and Electronics Engineering from Kumaraguru College of technology, Bharathiyar University, Coimbatore, India and M.E. degree in Power systems engineering from Annamalai University, Chidambaram, India. $\mathrm{He}$ is currently working as an Assistant Professor in Department of Electrical and Electronics Engineering, Jayaram college of engineering and technology, Pagalavadi, Thuraiyur, India. His research interest includes Restructured power system and smart grid technologies.

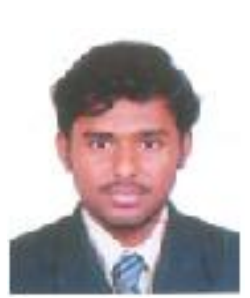

Saravanakumar $\mathbf{R}$ received his B.E. degree in Electrical and Electronics Engineering from PSNA College of engineering \& technology, Dindigul, Anna University, Chennai, India and M.E. degree in Power systems engineering from University College of engineering, BIT campus, Trichirappalli, India. $\mathrm{He}$ is currently working as an Assistant Professor in Department of Electrical and Electronics Engineering,Sudharsan engineering college, Sathiyamangalam, India. His research interest includes power systems and Distributed Generation. 